\title{
Re-Assessing the New York City Seismic Design Building Code
}

\author{
Zoya Susan Benyaminov \\ NYU School of Engineering, 6 MetroTech Center, Brooklyn, NY 11201, United States \\ of America
}

Tel: 1-347-777-5939_E-mail: zsb214@nyu.edu

Merins Sadiku

NYU School of Engineering, 6 MetroTech Center, Brooklyn, NY 11201, United States of America

Tel: 1-347-445-5161_E-mail: ms7483@nyu.edu

Mishka Stueber (Corresponding Author)

NYU School of Engineering, 6 MetroTech Center, Brooklyn, NY 11201, United States of America

Tel: 1-347-379-3945_E-mail: mas1268@nyu.edu

Received: March 19, 2017 Accepted: March 29, 2017 Published: June 30, 2017

doi:10.5296/jee.v8i1.10940ＵRL: https://doi.org/10.5296/jee.v8i1.10940

\begin{abstract}
This paper addresses the need for reassessment and revision of the New York City Seismic Design Building Code to include reinforcing existing structures that were built before 1995. Although earthquakes in New York City are rare, the combination of its geology and pedology allow for little damping and the lack of adequate reinforcement in existing structures have the potential to amplify the consequences of otherwise small events. The NYC Building Code of 1995 requires new structures to be designed against seismic activity, but does not require the addition of seismic reinforcement for existing buildings. In an effort to fill this gap, a case study of Brooklyn Brownstones is presented, illustrating the concern for unreinforced masonry (URM) buildings and describing the cultural and economic
\end{abstract}




\section{Macrothink}

implications of reassessment. This case study, in combination with a literature review and commentary, supports the need for an updated seismic building code. Reassessment will not only preserve culturally significant structures like the Brooklyn Brownstone, but also provide standards for a more resilient infrastructure that will keep New York City operating through greater magnitude events.

Keywords: New York City, Seismic design, Building code, Earthquake, Brownstone, Unreinforced masonry building 


\section{Introduction}

The New York City metropolitan region spans three states: New York, New Jersey and Connecticut, It has a combined population of about 22 million. New York City is the largest city in the United States, with a population of 8.2 million. NYC and the surrounding suburbs contain major centers of international finance, trade, new and traditional media, real estate, education, fashion, biotechnology, and manufacturing. It is one of the most important economic regions in the United States and a major financial center of global commerce. New York City is a frequent travel destination, hosting 55 million tourists and business people each year. These visitors and the city's residents live, work, play, heal, and worship in about one million structures, including homes, office buildings, religious and community centers, hospitals, and historic sites.

Ensuring public safety is a top priority for those attempting to govern this large, often unruly metropolitan area. Police, fire, traffic, and other municipal, state, and federal health and security-related agencies are allocated significant portions of the region's tax dollars in order to protect those living, working in, and passing through the area. One element of the public safety paradigm that needs to be reconsidered periodically is that related to the risks and consequences of a high magnitude earthquake (greater than 5.0 Richter scale) on New York City buildings and infrastructure.

\section{Earthquake History}

Although New York City does not sit directly on active fault lines, intraplate earthquakes do occur in the northeastern United States. These take place within the North American tectonic plate rather than its boundaries: California to the west and the Atlantic Ocean mid-ocean ridge to the east. This is a phenomena that is not yet fully understood and is not easily reconciled with traditional plate tectonic theory (Ebinger and Horowitz, 2015).

While it is unlikely for a high magnitude earthquake to have its epicenter in New York City, portions of New York State are seismically active, as shown on Figure 1. The U.S. Geological Survey's (USGS) record of intraplate earthquakes within the metropolitan region dates back over 400 years to 1638. More recently, since the early 1970s New York State has experienced numerous earthquakes, the most intense being the Blue Mountain Lake earthquake (magnitude 5.3 in 1983) in the northern Adirondacks (USGS, 2012). The most damaging earthquake on record in New York State was a 19445.8 magnitude event near Massena. Ground motion associated with that earthquake was reported over a 450,000 square mile area ranging from western Maine, to Indiana, through Canada, and into Maryland. New York State recorded five measurable earthquakes in 2014; eight in 2015, and 12 in 2016 (Earthquake Track, 2017). 


\section{I Macrothink}

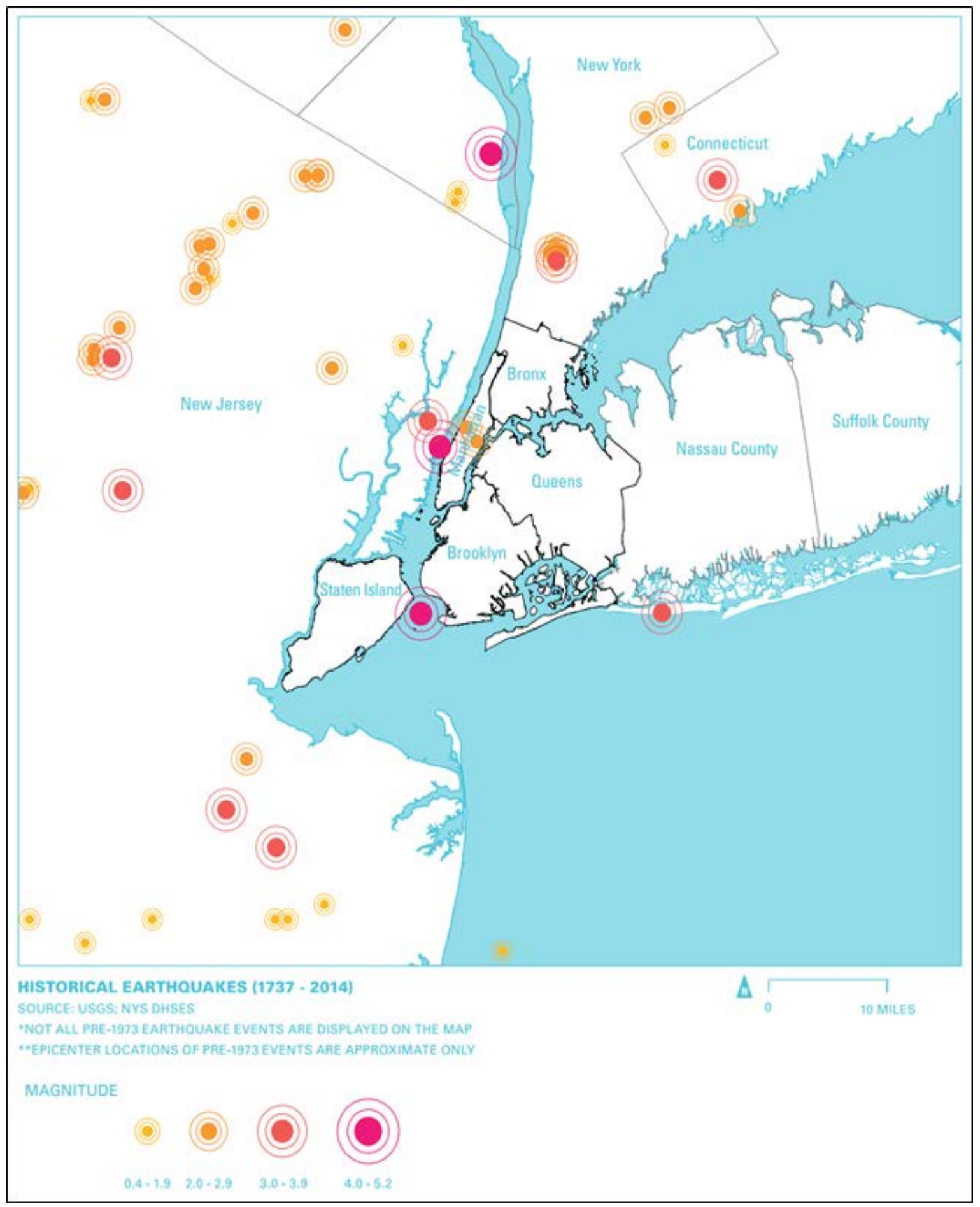

Figure 1. Historical Earthquake Magnitudes in NYC from 1737 to 2014 (Lenten, 2014)

A magnitude 5.2 earthquake is the largest New York City has experienced. The earthquake of 1884 was the last 5.2 magnitude seismic event that directly affected New York City, resulting in no deaths and damage limited to falling bricks and broken chimneys (Lenten, 2014). In 2002, New York City experienced a 5.1 magnitude earthquake, with an epicenter 15 miles southwest of Plattsburgh, New York (USGS, 2012). Again, there were no deaths or injuries and only slight damage was noted. 
Seismologists at Columbia University's Lamont-Doherty Earth Observatory have concluded that: "...magnitude six earthquakes take place in the [metropolitan] area about every 670 years, and sevens every 3,400 years" (Sykes et al., 2008). Given the limited historical data, an earthquake of magnitude six or even seven is possible, and becomes more probable as time proceeds. All that is required to cause a major disaster within New York City is one earthquake with a magnitude of over four or five, the benchmark against which most buildings have been designed to withstand. A stricter seismic code would reduce the risks and hazards of such a catastrophe and provide a much needed safety factor to bring new and re-developed structures into alignment with a more modern view of New York's seismic setting.

\section{Basis for the Current Seismic Code}

In evaluating the protectiveness of the current New York City seismic building code, it is important to not only review the past distribution of earthquakes but also to consider the possible extent of damage to current structures. In the 1980s, a study by an ad hoc seismology committee of the New York Association of Consulting Engineers described the city's seismicity as "moderate." They found that earthquakes with magnitudes greater than 5.0 occur in the metropolitan region about once every 100 years, which means there is little chance that the citizens and property of the area are at significant risk (Nordenson, et al., 2000).

Although the risk for high magnitude earthquakes has a low probability of occurring in New York City, its geology and pedology allow for little damping and dissipation of ground motion accelerations that are generated. New York City has a thin layer of soil above its crystalline bedrock. This permits the efficient transmission of non-attenuated seismic waves over large areas which greatly reduces the ability of structures to withstand a high magnitude event (Lenten, 2014). Since most structures built before 1995 were not designed specifically for seismic strength, there is risk associated with a high magnitude earthquake occurring in the area, especially since the near surface nature of the bedrock prevents dissipation of energy.

Another limiting aspect of the area to withstand moderate to high magnitude ground accelerations is the type of soil that is present. The various types of New York City soil have been classified as Category $\mathrm{C}$, meaning that sites should be evaluated for slope instability, liquefaction, settlement and surface displacement due to faulting. A Category $\mathrm{C}$ soil class is composed of very dense soil and soft rock, which is the case for much of the Manhattan area, as seen in Figure 2. When considering older structures, it is unlikely that the necessary soil inspections were conducted, placing the foundations of these structures at risk. 


\section{$\Lambda$ Macrothink}

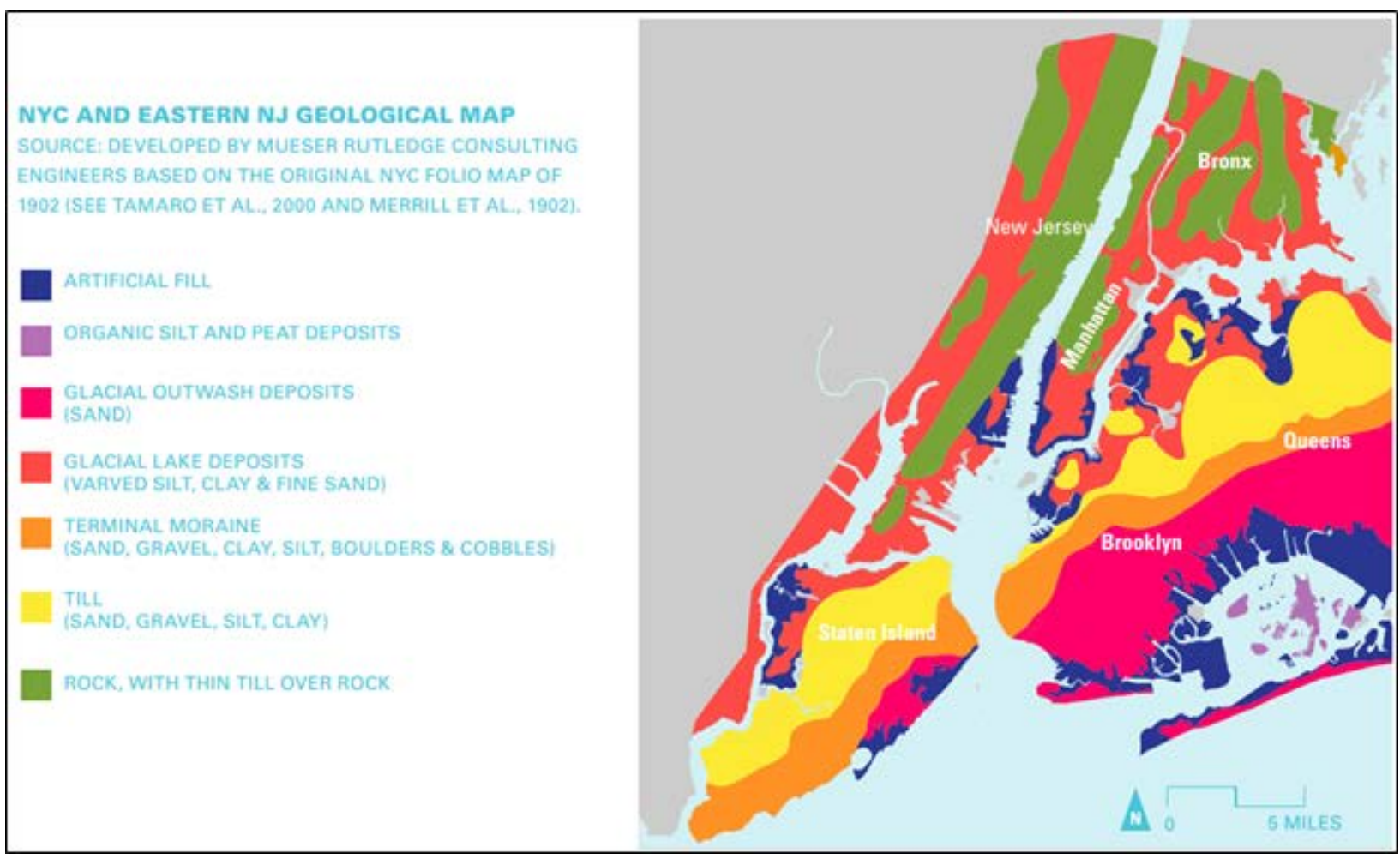

Figure 2. NYC and Eastern NJ Geological Map (Lenten, 2014)

Because the safety of people as well as integrity of the regional economy is paramount, in 1995 New York City established its first Seismic Building code design standard. These regulations were based upon the International Building Code (IBC) and were updated in 2008, eventually incorporating the American Society of Civil Engineers Standard (ASCE 7) a few years later in 2010. The difference between the IBC and the ASCE 7 is that the International Code is used to design a new structure for a two percent chance that a moderate earthquake (magnitude 5.0) would occur in a 50 year period. ASCE 7, however, considers a risk-based approach that accounts for the probability of a new structure collapsing during an earthquake. Instead of designing for the probability of an earthquake occurring, the New York City code mandates a higher standard by requiring design based on the probability of collapse (Lenten, 2014).

The U.S. Geological Survey has classified New York City as having an intermediate risk hazard for seismic activity, which reinforces the widespread assumption that there is no need to update the existing building code. The New York City building code seismic requirements refer to Chapter 11 of ASCE 7-10 to determine the risk category of new construction (Table 1). In general, the risk category of buildings in New York City are designated I, II, or III. Newer structures, built in New York City after 2010, are Risk Category I as they were constructed using the ASCE 7-10 standards adopted in 2010. Whereas older structures, not built to these standards, are in a higher risk category. 
Table 1. ASCE Risk Categories of Buildings for Earthquake Loads (ASCE 7-10 Table 1.5-1)

\begin{tabular}{l}
\hline Use or Occupancy of Buildings and Structures \\
\hline Buildings and other structures that represent a low risk to human life in the event of failure \\
All buildings and other structures except those listed in Risk Categories I, III, and IV \\
Buildings and other structures, the failure of which could pose a substantial risk to human life. \\
Buildings and other structures, not included in Risk Category IV, with potential to cause a substantial \\
economic impact and/or mass disruption of day-to-day civilian life in the event of failure. \\
Buildings and other structures not included in Risk Category IV (including, but not limited to, facilities that \\
manufacture, process, handle, store, use, or dispose of such substances as hazardous fuels, hazardous \\
chemicals, hazardous waste, or explosives) containing toxic or explosive substances where their quantity \\
exceeds a threshold quantity established by the authority having jurisdiction and is sufficient to pose a threat \\
to the public if released. \\
Buildings and other structures designated as essential facilities. \\
Buildings and other structures, the failure of which could pose a substantial hazard to the community. \\
Buildings and other structures (including, but not limited to, facilities that manufacture, process, handle, store, \\
use, or dispose of such substances as hazardous fuels, hazardous chemicals, or hazardous waste) containing \\
sufficient quantities of highly toxic substances where the quantity exceeds a threshold quantity established by \\
the authority having jurisdiction to be dangerous to the public if released and is sufficient to pose a threat to \\
the public if released.
\end{tabular}

The New York City Building Code also establishes inspection criteria for Structural Tests and Special Instructions in Chapter 17 (NYCDDC, 2014). Although the code does include seismic activity aspects of construction and design for new buildings, it does not address updating existing structures. There is no assurance that structures built prior to 1995 will withstand a medium magnitude earthquake (between 5.0 and 6.0 on the Richter scale) and there is no set standard on how to evaluate this concern. In short, the code does not require existing structures to be reinforced for seismic activity. Older structures are likely to perform at Risk III. They are more susceptible to complete structural failure in the event of a magnitude five or greater earthquake, which can result in major damage with severe injuries and even fatalities.

While New York City's seismic hazard is considered to be relatively low, nonetheless it poses significant seismic risk due to the value of its infrastructure, density of buildings and population, and the age and fragility of its structures, many of which have not been designed for even moderate seismic events (Nordenson et al., 2000).

\section{Building and Infrastructure Integrity}

The majority of the occupied structures within the New York City metropolitan region are not the state-of-the-art high rises that make up the Manhattan skyline. Many date back over a century and are low-rise, unreinforced masonry (URM) or brick buildings which, when considered in terms of earthquake resiliency, are more susceptible to damage than more 
modern multi-story steel and reinforced concrete buildings.

Much of the infrastructure of New York City also dates back more than 100 years. This includes the city's (buried and surficial) horizontal systems such as sewers, electrical grids, gas lines, bridges, tunnels, roadways, and mass transit. Roughly 11 percent of the metropolitan region's bridges are more than 50 years old and in need of major repairs, 30 percent of the city's pavement is not in "good” shape - as determined by the state Department of Transportation - and a third of the city's water mains were laid underground before 1930 (Forman, 2014). One of the most pressing infrastructure concerns is a simple one: the location of a large amount of underground utilities is not known. This makes their routine repair, maintenance, or replacement problematic, especially under emergency conditions. Therefore, the age of this infrastructure must also be taken into consideration when analyzing the seismic risk of New York City.

When considering the seismic stability of old structures in New York City, it is important to also consider the cultural and historical aspects of these buildings. The quintessential postcard of Brooklyn includes the Brooklyn Bridge from Manhattan with the skyline as its backdrop, and a quiet string of brownstone and brick row houses looming along Brooklyn Bridge Park (Figure 3). Unreinforced masonry buildings such as brownstones are numerous in New York City, and are especially abundant in the Brooklyn neighborhoods of Park Slope, Clinton Hill, Fort Greene, Cobble Hill, Prospect Heights, Brooklyn Heights, Bedford Stuyvesant, Sunset Park, and Bay Ridge (combined 2014 population of 1.2 million). In these neighborhoods, brownstones make up 80 percent of the housing stock and are sought after for both their aesthetic and cultural value which have deep roots in New York City's history (Jones, 2001). Prices reflect their desirability; this year the average sale price for a brownstone building in northern Brooklyn reached \$1.4 million, a 6.7 increase from \$1 million in 2015 (Leon, 2016). 


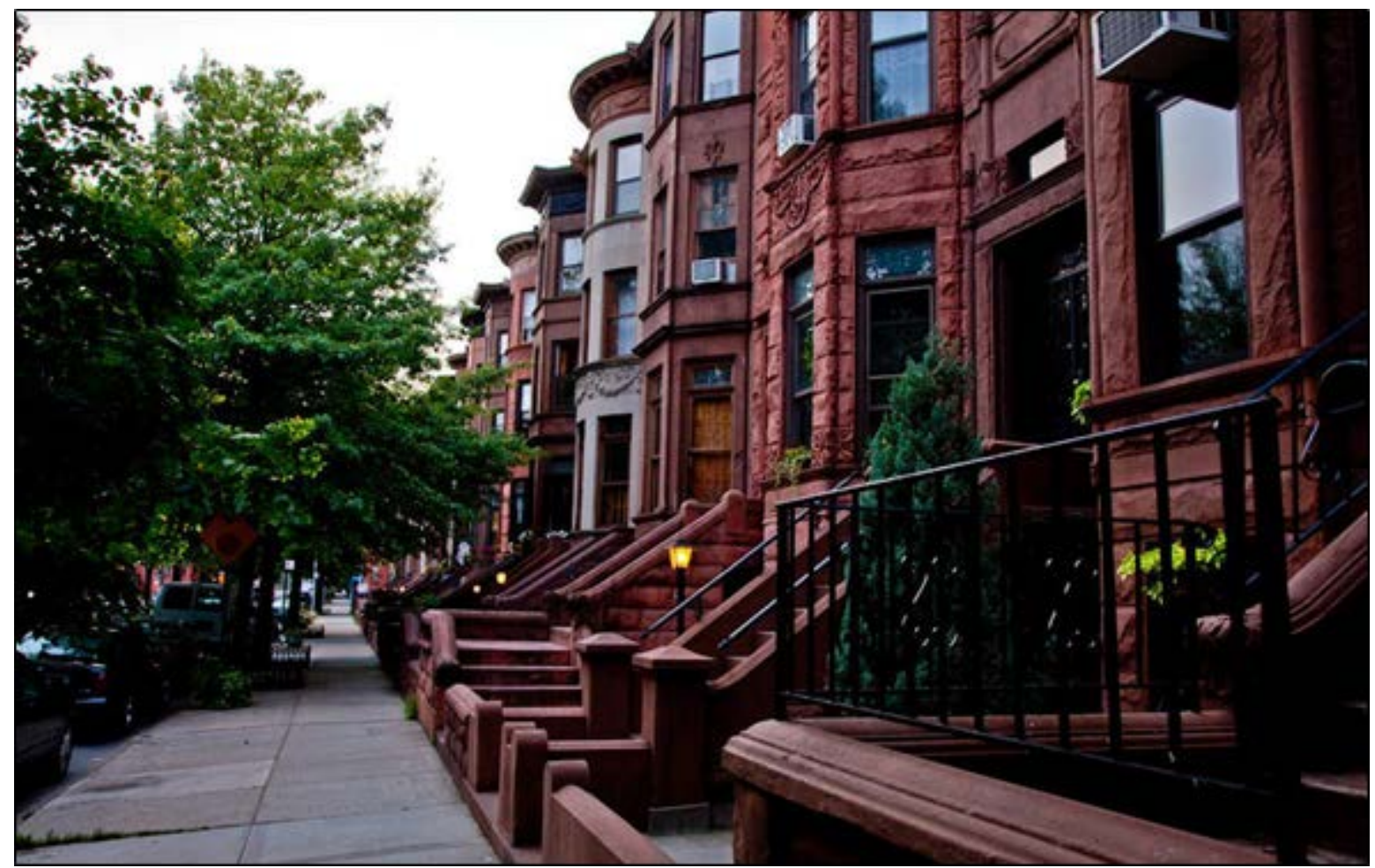

Figure 3. Brownstones in Fort Greene, Brooklyn

Although the New York City Building Code was updated in 1995 to include seismic design, most New York City structures were built well beforehand. These are at-risk, low rise, masonry structures that make up much of midtown Manhattan and Brooklyn and portions of Queens and the other boroughs. These structures lack the ductile capacity to resist seismic activity (ground accelerations).

Brownstones incorporate a cultural component to an otherwise primarily safety- and economic-based discussion. The brownstone was a popular building material in the 19th century, admired for its strength and reddish-brown color which provided a polished "front" for row houses built of less-expensive brick. Due to new mining techniques introduced in the 1860 s, it was cheaper than granite, marble, or limestone, making it a widely used material (NYHS, 2012).

Today, a "Brooklyn Brownstone" refers to these brownstone-fronted buildings. They are especially susceptible to damage from earthquakes due to the nature of their construction (Sigmund et al., 2016). This is because:

- $\quad$ Foundations are primarily rubble, with some brick appearing after 1900.

- $\quad$ The exterior walls are solid brick, framed only by wood joists spanning the width of the house coupling load-bearing side walls. There is rarely proper connection between the joists and the walls, as joists are typically rested on the edges of the walls they span (Figure 4). This missing connection results in the inability of the structure to transfer horizontal loads between floors and walls.

- $\quad$ Although they are masonry buildings, they are unreinforced (i.e., do not have interior 
bracing), and lack the strength of similar but more modern reinforced structures. Brownstones are also more prone to cracking due to cyclic in-plane shaking because they inherently have a low shear bearing capacity. In other words, repeated, reverse in-plane lateral movement is more likely to cause cracks due to the lack of interior bracing to resist it).

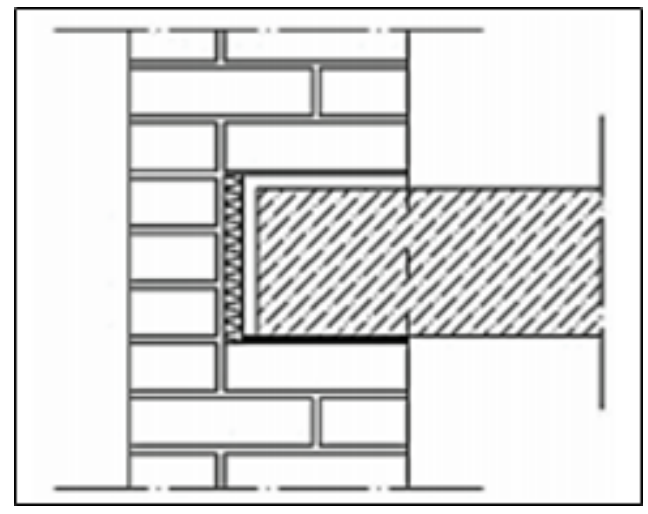

Figure 4. Typical Connection Between Joists and Walls Used in Brownstone Construction in 1860 Through 1920 (ElGawady et al., 2004)

The challenges in preserving brownstones are primarily related to addressing earthquake effects using mitigation techniques that do not impact the appearance or livability of the building. But perhaps an even greater obstacle is finding a cost-effective way to retrofit these buildings. Acknowledging this challenge, a team of engineers from the University of Zagreb created a strengthening selection process which guides the user to select mitigation options based on the weakest point of each structure. Through an iterative cost evaluation, possible strengthening techniques can be assessed (Bradley, 1979).

Retrofitting measures may take a number of forms, with the most probable being reinforcing the masonry walls with steel braces and anchors at floor and parapet connections in order to provide joints with additional strength. In a study performed by the Multidisciplinary Center for Earthquake Engineering Research (MCEER) in collaboration with the State University of New York at Buffalo, a shake table test was used to analyze the response of a model row house to cyclic loading mimicking an earthquake. Two walls, one reinforced and one unreinforced, were placed side by side on a shake table and subjected to earthquake conditions similar to those experienced during a low magnitude tremor recorded in New York City in August 2011.

As expected, the unreinforced wall failed, beginning with the collapse of the parapet at its disconnected joint. Additionally, sliding failure occurred at the connection of the floor diaphragm on the reinforced wall. The latter was unexpected, but serves to illustrate the importance of investing in further analysis of seismology in New York City and encourages reassessment of New York City’s seismic building code (Dargush, 2001).

Another solution to retrofitting the Brooklyn Brownstones involves injecting grout or epoxy into voids and cracks in their walls. Stitching may be used when especially large cracks call 
for the use of steel ties and mortar to hold them together. Through these techniques, the original stiffness of the wall is restored at low cost and without significant environmental impact (ElGawady, eet al., 2004). Unlike the bracing technique, this method can be equated to putting a bandage on a wound; it is an easy, quick fix but it does not repair the breaks in the walls.

Lastly, although not the most effective solution, re-pointing is a useful option on buildings where the bricks are of good quality but the mortar has deteriorated. In these scenarios, mortar of higher performance can be added, but this approach has been found to have little to no effect on the ultimate acceleration resistance of the structure (Bhattacharya, et al., 2014).

Brownstone buildings are unique in the sense that much of their value as a masonry structure comes from their aesthetic appeal. The fact that brownstone only is used as a "front" on these structures supports this. For that reason, other mitigation measures which require significant change to their façade have not been considered.

\section{Revise the Seismic Code?}

By amending the New York City building code to require reinforcement of existing structures, these buildings may have an improved ultimate load, displacement capacity, ductility, and energy dissipation in response to earthquake events (Konthesingha, 2015). The most concerning cases the New York City Building Code would need to consider are those related to unreinforced masonry buildings, many of which have historical value and will be costly to retrofit.

As described earlier, there are numerous ways to reinforce these structures to enhance their resistance to earthquakes, including parapet bracing, wall anchorage, out-of-plane bracing, or increased diaphragm reinforcing. These methods can be designed using ASCE 31-03 and ASCE 41-06 specification manuals for seismic evaluation and rehabilitation of existing buildings, respectively. Different structural solutions would be measured against added capacity and retrofit costs, thus determining the most practical approach for different portions of the metropolitan area (ASCE 31-03 \& 41-06). A preliminary estimate of the total approximate cost for reinforcing all New York City URM buildings is estimated at approximately $\$ 60$ billion (Table 2).

Table 2. Cost Estimate of Reinforcing Old URM Low Rise Buildings in New York City

\begin{tabular}{|l|l|}
\hline Number of Buildings in NYC & $1,000,000$ \\
\hline Number of Buildings Built Before 1995 in NYC (95\% of All Buildings) & 950,000 \\
\hline Number of Old URM Buildings Built Before 1995 in NYC & 332,500 \\
\hline Construction Cost of Typical 5-Story URM (4,000 ft^2/story) & $\$ 4,375,000$ \\
\hline $\begin{array}{l}\text { Cost of URM Seismic Reinforcement Per Building (4\% of Construction } \\
\text { Cost) }\end{array}$ & $\$ 175,000$ \\
\hline Approximate Total Cost & $\$ 58,187,500,000$ \\
\hline
\end{tabular}


To justify such a costly building improvement program, a reliable and meaningful cost-risk-benefit analysis will need to be performed by the appropriate institutional stakeholders. Such an analysis must include the cost of reinforcing existing structures versus the estimated savings measured against the probability of an intermediate level earthquake. In addition, the economic and societal impact of injuries, fatalities, and loss of public confidence in the engineering community and lawmakers also should be factored into the evaluation.

If new seismic code requirements are promulgated they likely will be phased in over some period of time and would require property owners to pay for them. Costs associated with retrofitting, depending on specific cases, could be substantial. It will fall on local building code officials, professional engineering and construction organizations, and other stakeholders in cooperation with lawmakers, to determine the benefit of such changes and protect homeowners and taxpayers from additional unnecessary expenses.

The main objective of a change in the New York City seismic code would be to improve the ability of older URM structures to withstand structural failure and thus limit serious injuries or fatalities. This would, in turn, decrease damage costs related to an earthquake. However, such aged structures are approaching the end of their useful life and eventually will need to be rebuilt. Depending on the specific case, it might not be economically feasible to undertake such major investment for an old building especially if it may soon need to be rebuilt with the required seismic resistance design criteria.

A typical four to five story URM residential structure has a useful life of 25-30 years, before requiring major repairs. The cost of adding seismic reinforcement, depending on the condition of each structure, could easily exceed the amount justifiable by damages from a predicted, 50 year, magnitude 5.2 earthquake. As seen from Table 1 above, such upgrades could cost a property owner nearly $\$ 175,000$.

An alternative to a blanket requirement for all structures is a much more limited version focusing just on buildings at risk of complete failure. By doing this, costs are limited to structures presenting the greatest risk of fatality. New York City contains a booming economy where older structures are constantly being brought down and replaced with new, better engineered ones. It is a reasonable decision to minimize such a major expense to homeowners when it is currently unclear whether the benefits of such a large scale spending decision outweighs its foreseeable costs.

\section{Discussion}

There are gaps in the vast safety and security infrastructures that operate across the New York City metropolitan area, particularly when it comes to natural disasters. The effects of Superstorm Sandy highlighted how ill-prepared the region was when this post tropical cyclone with hurricane force winds made landfall on October 29, 2012. Its storm surge flooded streets, tunnels, and subway lines and cut power in and around the area for many days. Similarly, the New York City metropolitan region also is not fully prepared for a natural disaster that would make the damage from Superstorm Sandy seem a minor inconvenience: an earthquake of magnitude five or greater. Both Superstorm Sandy and a magnitude five 
earthquake have a predicted occurrence frequency within the New York City area of 100 years (Tantala, 2003).

It is the responsibility of lawmakers and professional engineers to take necessary measures to protect the public and the reliability of the region's economy. However, the costs associated with achieving these goals must be defensible and justifiable to taxpayers and property owners. The risk to New York City from probable earthquakes is limited to slight to moderate damage to older, low-rise structures (as seen in previous earthquakes in the area). The benefits of revising the building code to require all existing structures to add seismic reinforcement currently does not justify the cost of such measures to homeowners.

However, it is important to sometimes look beyond just the economics of a proposition and to ask the question in a different way. What is it worth to help maintain the more intangible cultural aspect of brownstones and other types of architecture unique to the metropolitan region? The answer to this question might be that it is worth the investment, perhaps in some limited or focused way, to preserve these important cultural assets for generations to come.

A focused seismic reinforcement requirement, phased in over time, could be economically applied to older and poorly engineered, at-risk structures, to prevent fatalities and minimize structural damage. Perhaps such a plan, supported by tax or insurance incentives, would be an alternative and allow costs to be spread out over time in a manageable way. This would be a more thoughtful and consistent implementation of a public safety and infrastructure improvement program that reflects the actual risks involved.

\section{References}

ASCE. (2003). ASCE 31-03 Seismic Evaluation of Existing Buildings: American Society of Civil Engineers.

ASCE. (2007). ASCE 41-06 Seismic Rehabilitation of Existing Buildings: American Society of Civil Engineers.

ASCE. (2013). ASCE 7-10 Minimum Design Loads for Buildings and Other Structures: American Society of Civil Engineers.

Bhattacharya, S., Sanket, N., \& Sekhar, C. D. (2014). A Critical Review of Retrofitting Methods for Unreinforced Masonry Structures: International Journal of Disaster Risk Reduction, 7, 51-67. https://doi.org/10.1016/j.ijdrr.2013.12.004.

Bradley, D. M. (1979). Appraising Brownstones of Manhattan. Land Economics, 55(3), 176-185.

Dargush, A. S. (2001). Estimating Earthquake Losses for the Greater New York City Area: Multidisciplinary Center for Earthquake Engineering Research.

Ebinger, C., \& Franklin, G. H. (2015). Identification of Faults and Crustal Loads, and Their Implications for Intraplate Seismicity in the Northeastern US: University of Rochester and Cornell University. 


\section{Macrothink}

ElGawady, M., Lestuzzi, P., \& Badoux. M. (2004). A Review of Conventional Seismic Retrofitting Techniques for URM: 13th International Brick and Block Masonry Conference Amsterdam: 1-10.

Forman, A. (2014). Center for Urban Future: New York City Center for an Urban Future.

Jones, J. (2013). Shake Test Gauges Seismic Vulnerability of NYC’s Row Houses. American Society of Civil Engineers, 83(4), 36-37.

Konthesingha, K. M. C., Masia, M. J., Petersen, R. B., \& Page, A. W. (2015). Experimental Evaluation of Static Cyclic In-Plane Shear Behavior of Unreinforced Masonry Walls Strengthened with NSM FRP Strips: Journal of Composites for Construction, 19(3). https://doi.org/10.1061/(ASCE)CC.1943-5614.0000512

Lenten, C. V. (2014). NYC’s Risk Landscape: A Guide to Hazard Mitigation: New York City Emergency Management.

Leon, A. (2016). Average Sale Price Hits \$1.4 Million in Brownstone and North Brooklyn: DNAinfo.

Nordenson, Guy J. P., \& Glenn R. B. (2000). Seismic Design Requirements for Regions of Moderate Seismicity. Earthquake Spectra, 16(1), 205-225. https://doi.org/10.1193/1.1586091.

NYCDDC. (2014). NYC Building Code: New York City Department of Design and Construction.

NYHS. (2012). Why Was Brownstone Used to Build Row Houses in NYC? New York Historical Society. [Video File].

Sigmund, Z., Mladen R., \& Damir L. (2016). Decision Support Model for Seismic Strengthening Technology Selection of Masonry Buildings. Technical Gazette, 23(3), 791-800. https://doi.org/10.17559/TV-20151208142529.

Tantala, M. (2003). Earthquake Risks and Mitigation in the New York/New Jersey/Connecticut Region: The New York City Area Consortium for Earthquake Loss Mitigation. MCEER-03-SP02.

\section{Copyrights}

Copyright for this article is retained by the author(s), with first publication rights granted to the journal.

This is an open-access article distributed under the terms and conditions of the Creative Commons Attribution license (http://creativecommons.org/licenses/by/4.0/) 